\title{
The weekend-dividend effect in the Spanish market.
}

\author{
Javier Gardeazabal and Marta Regúlez*i \\ University of the Basque Country
}

24th June 2002

\begin{abstract}
In this paper we develop an econometric test of a corollary of the irrelevance of the dividend policy principle, namely, that the rescheduling of dividends does not affect the market valuation of the firm. In particular, the market value of the firm should not change if the firm reschedules dividends from one day to another day. This proposition is tested by regressing daily stock returns on a weekend dummy, a dividend dummy and their interaction. The first two variables should capture the weekend and dividend effects. The interaction term should be insignificant if rescheduling of dividends does not affect the market valuation of stocks. Formal econometric evidence finds no indication of a significant weekend effect, though, at the individual level, some stocks yield abnormal returns on ex-dividend days and when dividends are scheduled on days after weekends or holidays. Firms could partially make up the price drop on ex-dividend days by scheduling dividend payments after a weekend or a holiday. However, the evidence suggests that firms do not use such policy.
\end{abstract}

* Javier Gardeazabal: Dpto. Fundamentos del Análisis Económico, Universidad del País Vasco, Avda. Lehendakari Aguirre 83, 48015 Bilbao, Spain. E-mail: jepgamaj@bs.ehu.es. Marta Regúlez: Dpto. Economía Aplicada III, Universidad del País Vasco, Avda. Lehendakari Aguirre 83, 48015 Bilbao, Spain. E-mail: etprecam@bs.ehu.es.

${ }^{\dagger}$ We would like to thank the hospitality of the Department of Economics at the University of California, Santa Cruz and the Spanish Ministerio de Educación y Cultura for (PR2000-0220, PR2000-0221, BEC2000-1393), Basque Government (PI-1999-131) and University of the Basque Country (9/UPV 00035.321-13511/2001) for financial support. 


\section{Introduction.}

Miller and Modigliani (1961), henceforth M\&M, showed that, given the investment policy of the firm, its dividend policy should not affect its market valuation. In other words, given investment policy, the market value of a firm should be the same whether the firm increases dividends and floats new shares or decreases dividends and relies on retained earnings. An immediate, but usually overlooked, corollary of M\&M's theorem is that rescheduling dividends has no effect on the market value of the firm. To understand this corollary consider a firm with a given dividend policy and the effect of the following dividend policy changes. First, for a given investment policy, the firm decides at time $t_{0}$ to reduce dividend payments by $D$ at time $t_{1}\left(t_{1}>t_{0}\right)$ increasing retained earnings in the same quantity, this should not change the firm's market value at $t_{0}$. Second, neither should the market value of the firm change if the same firm, with the same investment policy, at $t_{0}$ decides to increase dividend payments at some future time $t_{2}\left(t_{2}>t_{1}\right)$ by $D(1+r)$ reducing its retained earnings in the same figure (where $r$ is the rate of return on the risk-free asset over the interval of time between $t_{1}$ and $t_{2}$ ). Combining both policy changes into one results in a rescheduling of dividend payments from $t_{1}$ to $t_{2}$ that does not affect the market valuation of the firm at $t_{0}$.

In this paper we develop an econometric test of this corollary. To be more precise a test of a necessary implication of the corollary: the market value of a firm should not change if the firm reschedules dividends from one day to another day. In order to carry out this test we take into account two empirical facts. First, when firms pay dividends to stock holders, share prices should experiment a proportional fall. If trade is continuous and frictionless, the difference between the cum-dividend price and the ex-dividend price must be identically equal to the dividend flow. However, it is a well documented fact that, on average, the price fall in the ex-dividend date is smaller than the amount of the dividend paid. Therefore returns are positive on average on the ex-dividend date. Several theoretical explanations of this empirical finding have been given in the literature. Different taxation of dividend and capital gains is the leading explanation of this phenomenon as suggested by Elton and Gruber (1970). Other explanations include microstructure arguments as in Frank and Jagannathan (1998). Second, in a perfect market with continuous and frictionless trading there should not be any pattern of seasonality in returns. However, it is also a well documented fact that daily returns exhibit seasonality. The weekend effect has been attributed to the absence of trading during weekends and holidays in a market where the flow of information does not stop, as suggested by French (1980). Other explanations include the technology of the clearing system, as in Lakonishok 
and Levi (1982).

The empirical evidence provided in this paper is based on the Spanish stock exchange market. On average, Spanish stock prices fall ex-dividend dates but, contrary to the US case, in the Spanish stock market the weekend effect manifests itself positively on returns, as returns tend to be higher after a weekend or a holiday. When dividend payment is on a day following a weekend or a holiday, returns ought to reflect the combined weekend and dividend effect. The question remains whether this combined effect should simply be the sum of the two effects or should be greater than the sum. In a perfect market the combined effect should be just the sum of the two effects. For suppose that markets were perfect, other than for the dividend and weekend effect, and at the same time, the combined effect was greater than the sum. Then, a change in the dividend payment policy moving ex-dividend dates to days following weekends or holidays will generate an unjustified abnormal return. In other words, rescheduling dividends to days following weekends or holidays will alter the market valuation of the firm, violating M\&M's irrelevance of dividend policy principle.

Regardless of whether dividend rescheduling has an effect on the market valuation of stocks, there is at least one other reason why managers might be interested in rescheduling dividends as a way of making up the price fall of ex-dividend dates with the positive average return of ex-weekend days (days following a weekend or a holiday). In this paper we also analyze whether Spanish firms follow such a policy of making up the price fall of ex-dividend dates.

The rest of the paper is organized as follows. Section 2 reports the differences in mean returns among ex-dividend days, days following weekends and holidays and other days. Section 3 searches for statistically significant differences in mean returns in ex-dividend days and days following weekends or holidays. Section 4 extends the analysis by controlling for common risk factors in stocks returns. Section 5 analyzes whether Spanish firms follow a policy of paying dividends days after weekends and holidays. Finally, section 6 concludes. A description of the data set and transformations is included in the appendix.

\section{The dividend and weekend effects.}

We collected daily close-to-close stock price data from Madrid's stock market from January 2, 1998 to December 29, 2000, for a total of 748 daily observations. We restricted the analysis to firms with complete data for the sample period, this resulted in a sample of 81 stocks. See appendix A for a detailed 
description of the data set and computations.

The Spanish stock market exhibits dividend and weekend effects. To be more precise, average returns are higher on ex-dividend dates and following a weekend or a holiday. ${ }^{1}$ Table 1 presents average returns, across stocks and days. On average, returns are $0.123 \%$ on ex-weekend days and $-0.004 \%$ on non-ex-weekend days. The average return on ex-dividend days is $0.347 \%$ versus a $0.022 \%$ on non-ex-dividend days. Both, the ex-weekend and exdividend days seem to have a larger return on average. Moreover, the average return on stocks on ex-dividend days that are also ex-weekend days is $0.494 \%$, quite above the overall mean return $0.024 \%$.

On average, ex-dividend dates exhibit positive returns despite the fact that stock prices fall. In this sample, the average price fall on ex-dividend days is 0.27 Euros and the average dividend is 0.30 Euros. In other words, on average, the price fall is smaller than the dividend. Figure 1 plots the dividend yield and capital gain from holding the stocks that paid dividends on ex-dividend dates. Two stylized facts can be observed. First, along the negatively sloped line the price drop is equal to the dividend payment. In fact, most observations are to the right of the negatively sloped line, indicating positive returns on ex-dividend dates. Second, a visual inspection of the graph indicates that most observations are to the left of the vertical line, indicating that, on average, prices fall on ex-dividend days.

\section{Formal tests of the dividend and weekend ef- fects.}

In order to test the statistical significance of the differences in mean returns due to weekend and dividend effects, we run the following pooled regression

$$
R_{i t}=\alpha+\beta^{w} W_{t}+\beta^{d} D_{i t}+\beta^{w d} W_{t} D_{i t}+u_{i t},
$$

where $R_{i t}$ is the return of stock $i$ in period $t$ in excess over the risk free return, $W_{t}$ is a dummy variable that takes the value of one on ex-weekend days and zero otherwise, $D_{i t}$ is a dummy variable that takes the value of one if stock $i$ pays a dividend on day $t$ and zero otherwise and $u_{i t}$ is a zero mean disturbance. In a perfect and friction-less market one should expect the estimates of $\beta^{w}, \beta^{d}$ and $\beta^{w d}$ not to be significantly different from zero. However, if stock prices tend to fall by less than the amount of dividend payment, the estimate of $\beta^{d}$ should be positive and significantly different from

\footnotetext{
${ }^{1}$ In all those cases when dividends were paid on days when the stock market was closed, the dividend payment was assigned to the next day the market opened.
} 
zero. On the other hand, the presence of daily seasonality may generate an estimate of $\beta^{w}$ significantly different from zero. Finally, if we find an estimate of $\beta^{w d}$ positive (negative) and significantly different from zero, it would be an indication that rescheduling of dividends from non-ex-weekend days to ex-weekend days (viceversa) would generate and abnormal positive return.

The results of fitting equation (1) by OLS are reported in columns (1) to (4) of Table 2. This table reports two sets of standard errors, both robust to heteroskedasticity, but the second set of standard error estimates is consistent even when there is cross-sectional correlation, that is, $E\left(u_{i t} u_{j s}\right) \neq 0$ for $t=s .^{2}$ Considering the first set of standard errors, both the ex-dividend and the ex-weekend dummies are significant in their individual regressions. They remain significant when both dummies are included in the regression and only the ex-weekend dummy is statistically significant in the regression with both dummies and their interaction. These results seem to indicate that stock returns exhibit ex-dividend as well as ex-weekend effects. However, the interaction of these two effects seems to be insignificant. These results indicate that returns on ex-dividend and ex-weekdays dates are higher. This, in turn, suggests that returns on Spanish stocks exhibit dividend and weekend effects. However, the fact that the interaction is not significant is an indication that no abnormal returns are obtained by scheduling dividend payments on ex-weekend days.

Considering the second set of standard errors, however, only the exdividend dummy is significant in its individual regression and in the one with the ex-weekend dummy. None of the dummies is significant once the interaction is included. The results, in particular the existence of a weekend effect, depend on how we compute the standard errors of the regressions. The second set of standard error estimates allows for the possibility of correlation among disturbances of different stocks. This is a more plausible scenario when coefficients vary with stocks but restrict the coefficients to be equal across stocks in the pooled regression.

Consider now the regression equation

$$
R_{i t}=\alpha_{i}+\beta_{i}^{w} W_{t}+\beta_{i}^{d} D_{i t}+\beta_{i}^{w d} W_{t} D_{i t}+\varepsilon_{i t}
$$

where the coefficients are different for each stock. Further suppose that coefficients $\beta_{i}^{j}, j=w, d, w d$ can be written as $\beta_{i}^{j}=\beta^{j}+\widetilde{\beta}_{i}^{j}$ where $\widetilde{\beta}_{i}^{j}$ is

\footnotetext{
${ }^{2}$ The first set of standard errors does correct for possible heteroskedasticity of unknown form a la White (2001), but does not allow for correlation among distrubances of different stocks. Driscoll and Kraay (1998) show that heteroskedasticity robust standard errors that fail to account for cross secrion correlation are in fact inconsistent. The second set of standard errors is estimated using the multivariate regression framework of White (2001), this time allowing for cross section correlation.
} 
a zero mean random disturbance. Under this assumption, the regression equation (1) can be seen as applying to the regression equation (2) where $u_{i t}=\widetilde{\alpha}_{i}+\widetilde{\beta}_{i}^{w} W_{t}+\widetilde{\beta}_{i}^{d} D_{i t}+\widetilde{\beta}_{i}^{w d} W_{t} D_{i t}+\varepsilon_{i t}$, and $E\left(u_{i t} \mid W_{t}, D_{i t}\right)=0$. Under this assumption the cross sectional correlation may arise either because the disturbance term, $\varepsilon_{i t}$, is correlated for different stocks, or because the $\widetilde{\beta}_{i}^{j}$,s are correlated among stocks. Since it appears that there is some degree of heterogeneity in the coefficients, it seems to be more appropriate to consider the second set of standard errors when making inference in the pooled regression. Therefore, using the second set of standard errors, the results of Table 2 indicate that, on average, the coefficients on the ex-weekend, ex-dividend and interaction dummies are not significantly different from zero.

If coefficients are fixed or deterministic but vary with stocks we can estimate the coefficients of equation (2) for each individual stock. In this case there is an identification issue. Identification depends on whether the firm paid all, some or no dividends on ex-weekend days, or no dividends at all. Accordingly, Table 3 classifies stocks in four disjoint sets. Set $S_{1}\left(S_{2}, S_{3}, S_{4}\right)$ includes all firms that paid all dividends on ex-weekend days (some dividends on ex-weekend days, no dividends on ex-weekend days, no dividends at all). Column 3 of Table 3 reports the number of firms in each set. Column 4 of Table 3 shows the parameters identified for a firm $i$ belonging to a particular set $S_{j}$. Firms in $S_{2}$ have all parameters identified. For all $i$ in $S_{4}$, only $\alpha_{i}$ and $\beta_{i}^{w}$ are identified, as there are no observations on dividends for firms in this set. Parameters $\alpha_{i}, \beta_{i}^{w}$ and $\beta_{i}^{d}$ are identified for all $i$ in $S_{3}$, but $\beta_{i}^{w d}$ is not identified because firms in this set did not pay dividends on ex-weekend days. Finally, for all $i$ in $S_{1}$, parameters $\alpha_{i}$ and $\beta_{i}^{w}$ as well as $\beta_{i}^{d}+\beta_{i}^{d w}$ are identified, but cannot identify $\beta_{i}^{d}$ and $\beta_{i}^{d w}$ separately, as $D_{i t}=W_{t} D_{i t}$ for all $t$ and $i \in S_{1}$.

Henceforth the estimation results reported correspond to firms in $S_{2}$. There are two reasons for proceeding in this way. First, restricting the analysis to firms in $S_{2}$ is convenient because all parameters are identified. Second, the inference reported below is greatly simplified if the number of parameters is equal for all individuals.

We proceeded to estimate equation (2) by ordinary least squares for all firms in $S_{2}$. Since the number of estimated parameters is very large, we present the estimated parameter values and t-statistics in a graph. Figure 2 shows the parameter estimates and t-statistics (in absolute value) for all stocks. Each panel of Figure 2 contains the results for one explanatory variable in equation (2). The horizontal line represents the $95 \%$ confidence interval. For each stock, the pair of coefficient estimate and t-statistic (in absolute value) is represented by a small square. If the square falls outside 
the $95 \%$ confidence interval it is significantly different from zero. As a rule of thumb, we should expect to see $5 \%$ or less of the squares falling outside the $95 \%$ interval when the true coefficients are equal to zero. If we see more than $5 \%$ of the estimated coefficients falling outside the $95 \%$ confidence interval, it is an indication that some of the true coefficients are different from zero. Since there are 58 firms in $S_{2}$, we should not expect to see more than, approximately, three squares outside the $95 \%$ confidence interval when all parameters are identically equal to zero.

For most stocks, the estimated constant and ex-weekend coefficients fall inside the $95 \%$ confidence interval, indicating that neither the constant nor the ex-weekend dummy have explanatory power. Several stocks have estimated ex-dividend and interaction coefficients that fall outside the $95 \%$ confidence interval. The ex-dividend and interaction dummies seem to have some bearing in explaining conditional returns.

In order to formally test for heterogeneity we carry out the following hypothesis tests. First we test the null hypothesis $H_{1}: \beta_{1}^{j}=\beta_{2}^{j}=\ldots .=\beta_{N}^{j}$, that the coefficients of variable $j$ are equal for all stocks. Rejection of $H_{1}$ indicates that coefficients vary with individual stocks. When $H_{1}$ can not be rejected, it is interesting to test the null hypothesis $H_{2}: \beta_{1}^{j}=\beta_{2}^{j}=\ldots .=\beta_{N}^{j}=0$, that all coefficients are equal to zero. In addition, whenever the $H_{1}$ has been rejected, that is, when coefficients for all individuals are not equal, it is interesting to test the hypothesis $H_{3}: \beta_{1}^{j}+\beta_{2}^{j}+\ldots .+\beta_{N}^{j}=0$, that the average is equal to zero. Table 5 reports Wald test statistics using an estimate of the covariance matrix of coefficients robust to heteroskedasticity and possible correlation across disturbances of different stocks. Let us analyze the results one variable at a time. For the constant term none of the three null hypotheses can be rejected. Results for the weekend dummy exhibit an identical pattern. According to these results, the weekend effect is not significant. Results are different for the dividend dummy, as all three hypotheses are rejected. The dividend dummy affects individual stocks differently and has an average effect significantly different from zero. Finally, the case of the interaction dummy is the most interesting. The null of equality of coefficients is rejected, indicating that the scheduling of dividend payments on ex-weekend days affects stock returns significantly and heterogeneously. However, the null hypothesis of a zero average effect is not rejected, that is, the interaction effect is positive for some stocks and negative for others, with an average not significantly different from zero. 


\section{Controlling for common risk factors.}

In this section we extend the empirical investigation by controlling for common risk factors in the regressions. The conditional model is the Fama and French (1993) three factors model extended with the ex-dividend and exweekend dummies and their interaction. The regression equation is

$$
R_{i t}=\alpha_{i}+\beta_{i}^{m} R_{t}^{m}+\beta_{i}^{s} S_{t}+\beta_{i}^{b} B_{t}+\beta_{i}^{w} W_{t}+\beta_{i}^{d} D_{i t}+\beta_{i}^{w d} W_{t} D_{i t},+v_{i t}
$$

where $R_{t}^{m}$ is the market return (in excess over the risk free rate), $S_{t}$ is the return on a size portfolio and $B_{t}$ is the return on a book-to-market portfolio. ${ }^{3}$ These three variables are meant to capture risk factors common to all stocks.

Column 5 of Table 3 reports the ordinary least squares estimates of the pooled regression including the risk factors. According to the first set of standard errors the mean weekend effect is significantly different from zero, but the mean dividend and interaction effects are not significant. When correlation among disturbances of different stocks is accounted for and the second set of standard errors is considered, non of the dummy variables is significant. The common risk factors are highly significant.

The results of fitting (3) to individual stocks are reported in Figure 3. The results are almost identical to those reported in the last section. After controlling for common risk factors, the ex-weekend dummy is not significant for most stocks, whereas the ex-dividend dummy and the interaction remain significant for several stocks. This might be understood as indicating that dividend payment on ex-weekend days may yield abnormal returns. The interaction effect is positive for some firms and negative for others, with an average mean value close to zero. Formal tests of heterogeneity are reported in Table 4, columns 4 to 6 . The results are exactly the same as in the previous section. The null hypothesis of homogeneity, $H_{1}$, is rejected for the ex-dividend and interaction dummies. We cannot reject the null hypothesis that all coefficients are equal to zero, $H_{2}$, for the constant term and the exweekend dummy. Finally, we reject the null hypothesis of a zero mean effect, $\mathrm{H}_{3}$, for the ex-dividend dummy.

\section{$5 \quad$ Do firms pay dividends on ex-weekend days?}

The sample includes 60,588 daily returns and 430 dividend payments distributed among ex-dividend days and ex-weekend days according to Panel A of Table 5. According to Panel B, only $0.71 \%$ of all observations correspond to ex-dividend days and $22.33 \%$ correspond to ex-weekend days. Even

\footnotetext{
${ }^{3}$ See the appendix for the construction of these portfolios.
} 
though $22.33 \%$ of the days in the sample were ex-weekend days, $44.88 \%$ of all dividends were paid on ex-weekend days. In fact, according to the results of panel C, we cannot reject the null hypothesis of independence of $W_{t}$ and $D_{i t}$. Panel D reports a Probit regression of $D_{i t}$ on $W_{t}$ and $N D_{i}$ (number of dividends paid by firm $i$ during the sample period). The weekend dummy is highly significant. This evidence suggests that dividend payments are not randomly assigned to any day of the week. It could be the case that some firms follow a policy of dividend payment on ex-weekend days. Nine firms did not paid dividends during the sample period. If firms actually follow a policy of dividend payment on ex-weekend days, then we should observe all their dividend payments on ex-weekend days. There are seven firms in the sample whose dividends were all paid on ex-weekend days. Though most of the seven firms have few dividend payments, one firm paid 12 dividends on ex-weekend days. If dividend payment dates were assigned randomly, to observe all 12 dividend payments on ex-weekend days is an event of probability $=1.537 \times 10^{-8}$. We thus conclude that, at least this firm follows a policy of dividend payment on ex-weekend days. The evidence suggests that, with only one exception, dividend payment policy does not follow a pattern to take advantage of the ex-weekend effect so as to make up the price drop of ex-dividend days.

\section{Conclusions.}

In this paper we test a corollary of M\&M's irrelevance of the dividend policy principle, that the timing of dividends should not affect the market valuation of a firm. A glance at the Madrid's stock exchange data suggests that, on average, stock returns seem to be higher after a weekend or a holiday than after working days. Also, on average, returns on ex-dividend days are higher than on days with no dividend payments. Formal econometric evidence finds indication of insignificant weekend and significant dividend effects. Inference on individual stocks suggests that some stocks yield abnormal returns on ex-dividend days and when dividends are scheduled on days after weekends or holidays. However, the cross section average of the abnormal returns resulting from scheduling dividend payments on ex-weekend days is not significantly different from zero. For some stocks, returns are higher (lower) when they paid dividends after weekends, suggesting that they returns could be higher if they reschudule all their dividend payments to day after weekends (working days). Therefore the timing of dividends is not irrelevant. Finally, the evidence provided suggests that firms do not seem to follow a policy of paying dividend after weekends. 


\section{Appendix: The data set.}

We collected daily close-to-close stock prices from Madrid's stock exchange market for a sample period from January 2, 1998 to December 29, 2000 for a total of 748 daily observations. We restricted the analysis to firms with complete data for the sample period. This restriction eliminates all firms which entered the market during the sample period, had their quotation suspended or merged with other firm in the data file. This resulted in a sample of 81 firms. The total number of daily returns in the sample is equal to 60,507 . No firm issued equity on ex-dividend dates and only one split was on ex-dividend day.

During 1998 stock prices were quoted in Spanish pesetas and starting in January 4, 1999, quotations were in euros, thus requiring adjustment by multiplying the euro figures by the 166.386 pesetas/euro fixed exchange rate. Stock prices were also adjusted for splits. Then, daily returns were calculated and adjusted for dividends and equity issue (also adjusted for pesetas/euro conversion and splits). The return on the market portfolio was proxied by the rate of change of the general index of the Madrid Stock Exchange (IGBM) and the risk-free asset return was taken to be the return on the one-day public debt repurchase agreements. To construct the size and book-to-market portfolios, we used end of 1997, 1998 and 1999 book value and market valuation, this information was not available for 7 firms. Then, we proceed exactly as in Fama and French (1993) to compute the returns on the size and book-to-market portfolios. 


\section{References}

[1] Driscoll, J.C. and A.C. Kraay, 1998. Consistent covariance matrix estimation with spatially dependent panel data. Review of Economics and Statistics 80(4), 549-60.

[2] Elton, E. and Gruber, M. 1970. Marginal stockholder tax rates and the clientele effect. Review of Economics and Statistics, 52, 68-74.

[3] Fama, E.F. and F.R. French., 1993. Common Risk Factors in the Returns on Stocks and Bonds. Journal of Financial Economics 33, 3-56.

[4] Fama, E.F. and F.R. French., 1996. Multifactor Explanations of Asset Pricing Anomalies. The Journal of Finance 51(1), 55-84.

[5] Frank, M. and R. Jagannathan, 1998. Why do stock prices drop by less than the value of the dividend? Evidence from a country without taxes. Journal of Financial Economics 47, 161-188.

[6] French, K. R. 1980. Stock returns and the weekend effect. Journal of Financial Economics, 8, 55-69.

[7] Lakonishok, J. and M. Levi, 1982. Weekend effects on stocks returns: A note. The Journal of Finance, XXXVII, 3, 883-889.

[8] Miller, M. H. and F. Modigliani, 1961. Dividend policy, growth and the valuation of shares. The Journal of Business 34, 411-33.

[9] White, H. 2001. Asymptotic theory for econometricians. Academic Press. 
Table 1: Mean returns.

\begin{tabular}{|c|c|c|c|}
\hline & Ex-dividend & No ex-dividend & Total \\
\hline Ex-weekend & 0.494 & 0.118 & 0.123 \\
\hline No ex-weekend & 0.233 & -0.005 & -0.004 \\
\hline Total & 0.347 & 0.022 & 0.024 \\
\hline
\end{tabular}

Table 2: Regressions with dummies and common risk factors.

\begin{tabular}{|c|c|c|c|c|c|}
\hline Variables & $(1)$ & (2) & (3) & $(4)$ & (5) \\
\hline \multirow[t]{3}{*}{ Constant } & 0.00012 & -0.00013 & -0.00015 & -0.00015 & -0.00016 \\
\hline & $(0.00096)$ & $(0.00011)$ & $(0.00011)$ & $(0.00011)$ & $(0.00010)$ \\
\hline & $(0.00036)$ & $(0.00040)$ & $(0.00040)$ & $(0.00040)$ & $(0.00019)$ \\
\hline \multirow[t]{3}{*}{$D_{t}$} & 0.00325 & & 0.00298 & 0.00238 & 0.00240 \\
\hline & $(0.00122)$ & & $(0.00122)$ & $(0.00158)$ & $(0.00150)$ \\
\hline & $(0.00146)$ & & $(0.00144)$ & $(0.00176)$ & $(0.00141)$ \\
\hline \multirow[t]{3}{*}{$W_{i t}$} & & 0.00127 & 0.00124 & 0.00123 & 0.00047 \\
\hline & & $(0.00024)$ & $(0.00024)$ & $(0.00024)$ & $(0.00022)$ \\
\hline & & $(0.00092)$ & $(0.00092)$ & $(0.00092)$ & $(0.00045)$ \\
\hline \multirow[t]{3}{*}{$W_{t} D_{i t}$} & & & & 0.00139 & -0.00057 \\
\hline & & & & $(0.00248)$ & $(0.00230)$ \\
\hline & & & & $(0.00297)$ & $(0.00230)$ \\
\hline \multirow[t]{3}{*}{$R_{t}^{m}$} & & & & & 0.73043 \\
\hline & & & & & $(0.01004)$ \\
\hline & & & & & $(0.02285)$ \\
\hline \multirow[t]{3}{*}{$S_{t}$} & & & & & 0.37226 \\
\hline & & & & & $(0.01337)$ \\
\hline & & & & & $(0.02485)$ \\
\hline \multirow[t]{3}{*}{$B_{t}$} & & & & & 0.14340 \\
\hline & & & & & $(0.01100)$ \\
\hline & & & & & $(0.02304)$ \\
\hline
\end{tabular}


Table 3: Classification of Stocks.

\begin{tabular}{lccc}
\hline$(1)$ & $(2)$ & $(3)$ & $(4)$ \\
Sets & Dividends paid & Number of firms & Identified parameters \\
\hline$S_{1}$ & All on ex-weekend & 7 & $\alpha_{i}, \beta_{i}^{w}, \beta_{i}^{d}+\beta_{i}^{d w}$ \\
$S_{2}$ & Some on ex-weekend & 58 & $\alpha_{i}, \beta_{i}^{w}, \beta_{i}^{d}, \beta_{i}^{d w}$ \\
$S_{3}$ & None on ex-weekend & 7 & $\alpha_{i}, \beta_{i}^{w}, \beta_{i}^{d}$ \\
$S_{4}$ & None at all & 9 & $\alpha_{i}, \beta_{i}^{w}$ \\
\hline
\end{tabular}

Table 4: Tests of hypothesis.

\begin{tabular}{lrrrrrr}
\hline & $(1)$ & $(2)$ & \multicolumn{1}{c}{$(3)$} & \multicolumn{1}{c}{$(4)$} & \multicolumn{1}{c}{$(5)$} & \multicolumn{1}{c}{$(6)$} \\
\hline \multirow{2}{*}{ Constant } & \multicolumn{1}{c}{$H_{1}$} & \multicolumn{1}{c}{$H_{2}$} & \multicolumn{1}{c}{$H_{3}$} & \multicolumn{1}{c}{$H_{1}$} & \multicolumn{1}{c}{$H_{2}$} & \multicolumn{1}{c}{$H_{3}$} \\
& 46.8184 & 46.9044 & 0.0646 & 46.7947 & 46.8835 & 0.5040 \\
$W_{t}$ & $(0.8299)$ & $(0.8511)$ & $(0.7993)$ & $(0.8305)$ & $(0.8517)$ & $(0.4777)$ \\
& 58.0697 & 58.0882 & 1.7855 & 60.5441 & 60.6603 & 1.1746 \\
$D_{i t}$ & $(0.4357)$ & $(0.4720)$ & $(0.1815)$ & $(0.3492)$ & $(0.3802)$ & $(0.2785)$ \\
& 4760.2584 & 5443.9656 & 15.0254 & 1760.9079 & 2160.4303 & 22.8406 \\
$W_{t} D_{i t}$ & $(0.0000)$ & $(0.0000)$ & $(0.0001)$ & $(0.0000)$ & $(0.0000)$ & $(0.0000)$ \\
& 757.9356 & 776.1088 & 0.0000 & 525.6223 & 528.0785 & 1.8470 \\
$R_{t}^{m}$ & $(0.0000)$ & $(0.0000)$ & $(0.9986)$ & $(0.0000)$ & $(0.0000)$ & $(0.1741)$ \\
& & & & 663.6686 & 2784.2577 & 916.8938 \\
$S_{t}$ & & & & $(0.0000)$ & $(0.0000)$ & $(0.0000)$ \\
& & & & 1231.3881 & 1770.1573 & 140.3291 \\
$B_{t}$ & & & & 654.5774 & 876.5849 & 35.5597 \\
& & & & $(0.0000)$ & $(0.0000)$ & $(0.0000)$ \\
\hline
\end{tabular}

P-values within parenthesis. 
Table 5: Frequencies.

Panel A: Absolute frequencies

\begin{tabular}{l|cc|c}
\hline & $D_{i t}=1$ & $D_{i t}=0$ & Total \\
\hline$W_{t}=1$ & 193 & 13334 & 13527 \\
$W_{t}=0$ & 237 & 46824 & 47061 \\
\hline Total & 430 & 60158 & 60588
\end{tabular}

Panel B: Relative frequencies.

\begin{tabular}{l|rc|l}
\hline & $D_{i t}=1$ & $D_{i t}=0$ & Total \\
\hline$W_{t}=1$ & 0.0032 & 0.2201 & 0.2233 \\
$W_{t}=0$ & 0.0039 & 0.7728 & 0.7767 \\
\hline Total & 0.0071 & 0.9929 & 1.000
\end{tabular}

Panel C: Independence Tests.

\begin{tabular}{llll}
\hline Pearson's test & 127.07 & p-value & 0.0000 \\
Likelihood ratio test & 107.84 & p-value & 0.0000
\end{tabular}

Panel D: Probit regression.

\begin{tabular}{lrc}
\hline Dependent variable $D_{i t}$ & \\
\hline Regressor & Estimate & t-statistic \\
\hline Constant & -2.9966 & -71.56 \\
$W_{t}$ & 0.3931 & 10.64 \\
$N D_{i}$ & 0.0665 & 13.85
\end{tabular}




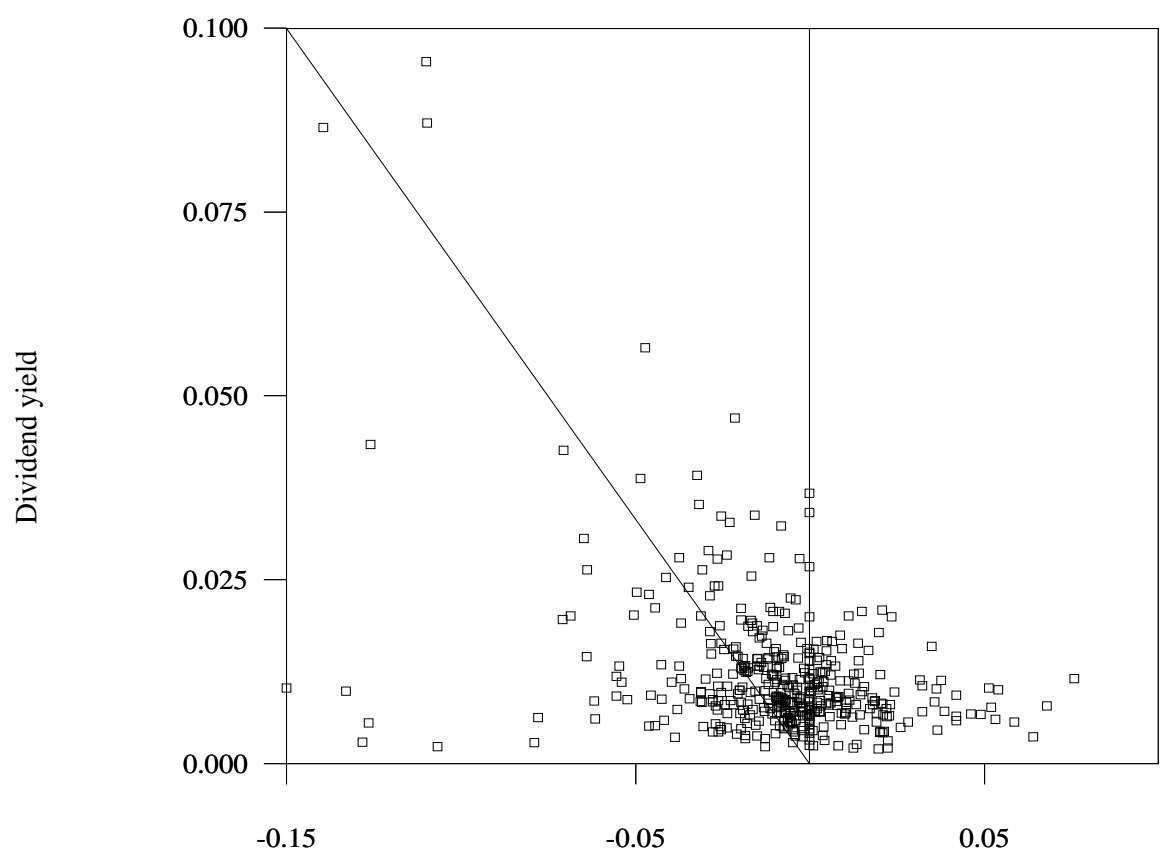

Rate of change of price

Figure 1: Dividend yield and rate of change of price. 

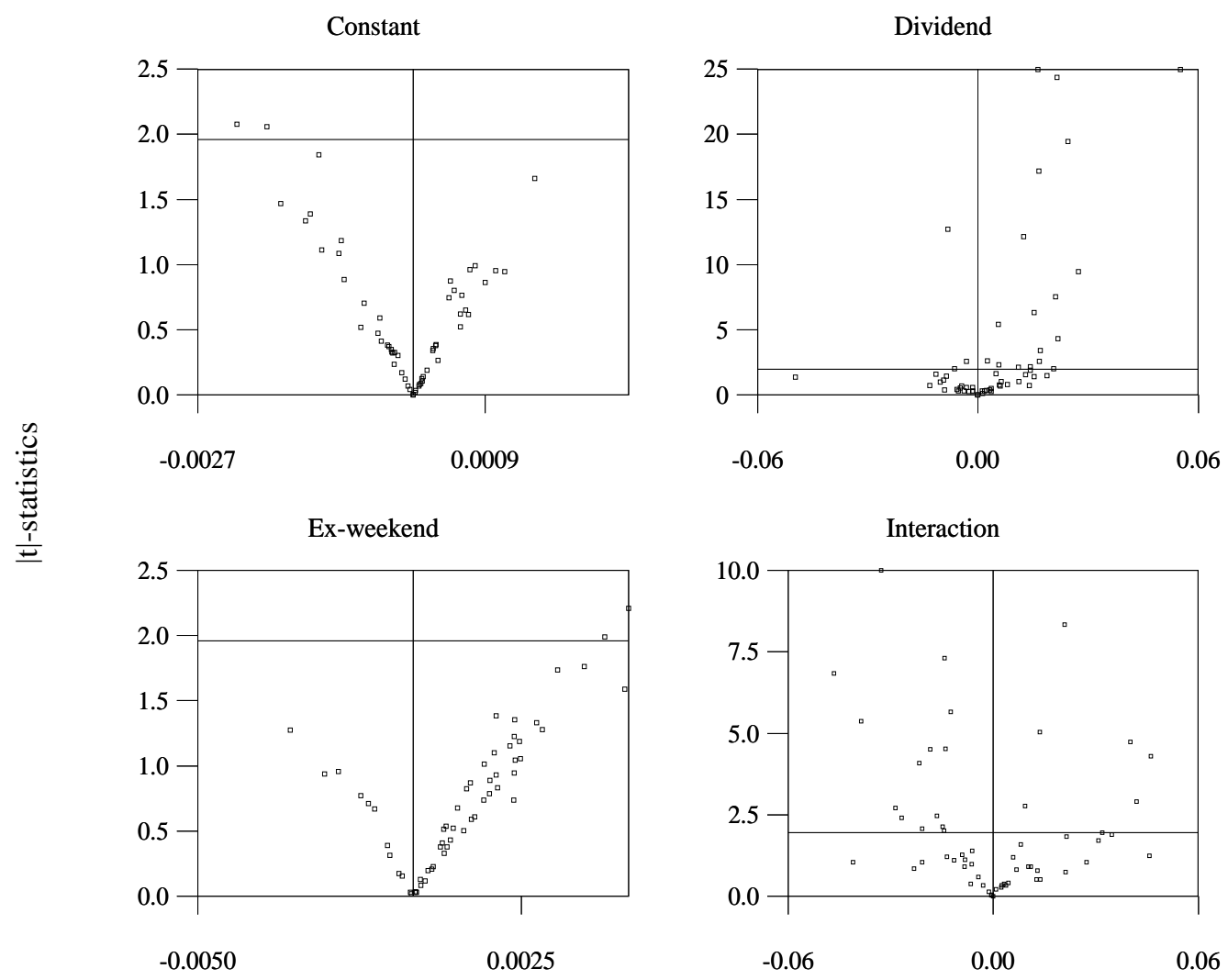

Parameter estimates

Figure 2: Parameter estimates and $|\mathrm{t}|$-values. Equation (2) 

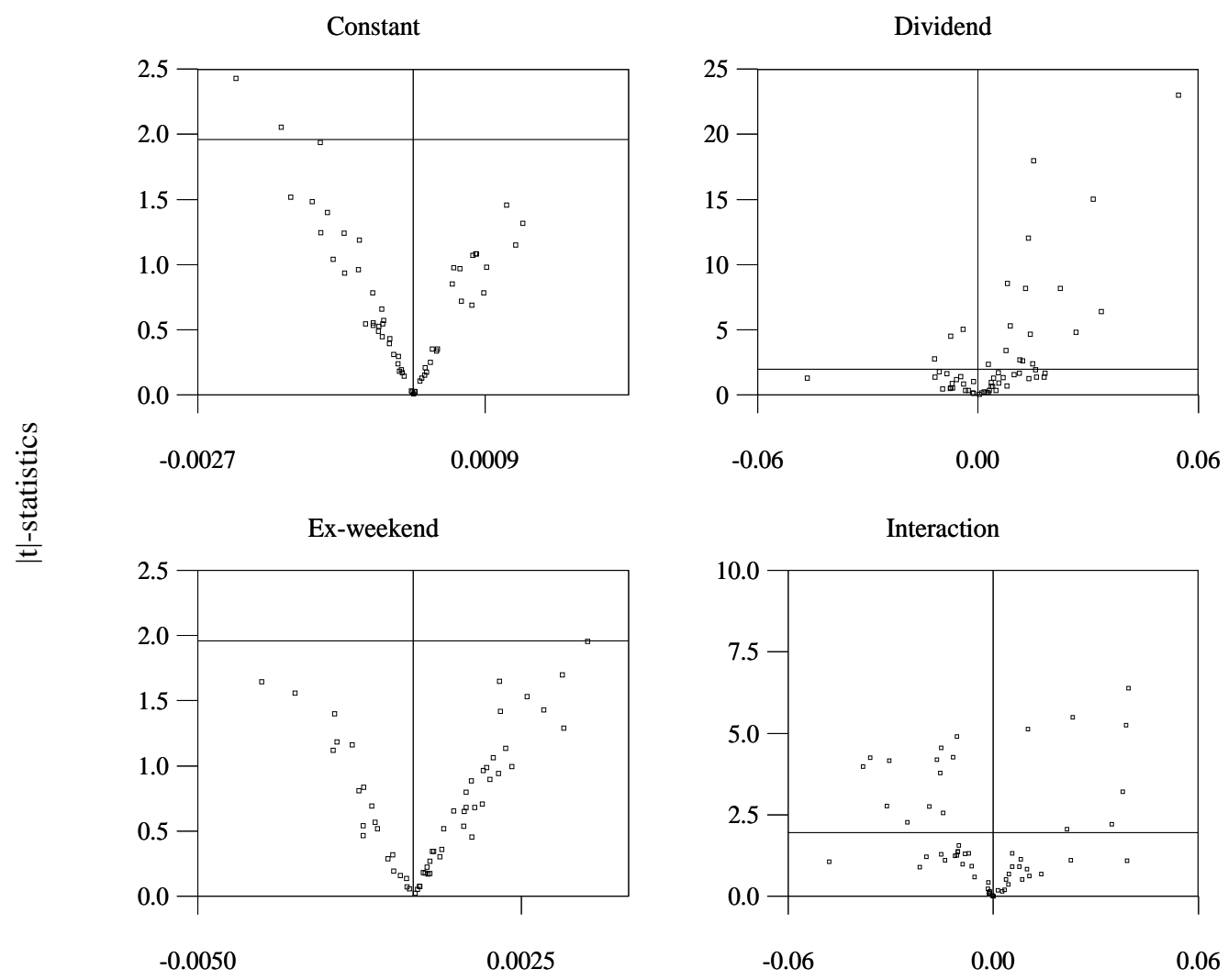

Parameter estimates

Figure 3: Parameter estimates and $|\mathrm{t}|$-values. Equation (3). 